\title{
Urban Community's Participation in Conservation of Open Spaces: A Case of Dar es Salaam City
}

\author{
Ahmad Hassan, Felister Mombo* \\ Department of Forest Economics, Faculty of Forestry and Nature Conservation, Sokoine University of Agriculture, Morogoro, Tanzania \\ Email address: \\ lununo@yahoo.com (A. Hassan), fmombo@yahoo.com (F. Mombo) \\ ${ }^{*}$ Corresponding author \\ To cite this article: \\ Ahmad Hassan, Felister Mombo. Urban Community’s Participation in Conservation of Open Spaces: A Case of Dar es Salaam City. \\ International Journal of Natural Resource Ecology and Management. Vol. 2, No. 1, 2017, pp. 9-19. doi: 10.11648/j.ijnrem.20170201.12
}

Received: December 20, 2016; Accepted: January 5, 2017; Published: February 3, 2017

\begin{abstract}
Open spaces in cities like Dar es Salaam are facing problem of encroachment and conversion. Despite scholars' recommendation on participatory approach in designing and execution of communities' project to increase participation including Conservation of Open Spaces (COSP). The study used questionnaire survey and participatory approach tools to gather information. Results show that majority of the respondents are aware of specific types and functions of existing open spaces in the study area. In general, most respondents were willing to participate in COSP. Quality, benefits, education and duration of residence were factors positively influencing households' willingness to participate in COSP.
\end{abstract}

Keywords: Open Spaces, Encroachment, Conservation, Participation, Awareness, Household, Willingness

\section{Introduction}

The quality of urban environment depends on the existence and abundance of open spaces. Open space in urban area is referred to as an urban green space private or public, principally covered by vegetation and directly or indirectly available for the users and may include parks, garden, allotments, wetlands, trees and forest [1-3]. Existence of open spaces in urban areas tends to decrease cost of living due to its effect on livelihood such as diseases, flooding, extreme weather change and psychological problem [4-5]. Furthermore, economies of green spaces in urban areas are not only emphasized by its role in biodiversity and nature conservation but also human health, pollution control, aesthetics recreation and ecosystem services they provide [13]. However, like other developing countries, Tanzania is facing many challenges on conserving open spaces such as conversion and encroachments of designated land for open spaces particularly in its rapidly growing cities like Dar es Salaam.

According to different studies conducted in Tanzania, the problem is initiated and accelerated by the rich, political leaders and retired government officials "who can bend rules and regulations" which result to residents acting likewise under the feeling that they will be under protection [6-7]. The designated use values of open spaces have been degraded which results to the disappearance of the spirit of ownership among the local community surrounding the open spaces. Other studies claim that, it is the failure of the "top-down" approach and lack of or poor involvement of local community in conservation of open spaces [7-8].

Playgrounds for children and social gathering have been converted to commercial/residential housing, encroached by small trade dwellers and others use as the waste collection centres [4, 6-7]. This results to children playing in the street roads while community gathering in the setbacks of building and paths of private lands that have been increasing risk of accidents and conflicts to the children and among members of communities respectively in Dar es Salaam [5].

In response to the growing reduction of open spaces due to encroachments and conversion of designated open spaces, Dar es Salam City Council (DCC) through Dar es Salaam Sustainable Project (DSP) established a working group, which organized meetings with ward executive officers, subward chairpersons and primary school teachers. The DCC required them to create public awareness and protecting invasion on open spaces. However, the state of unawareness of open spaces among public still exists but to which extent the locals are not aware is still unknown.

[8] evaluated performance of DSP in management of open spaces for urban poor and revealed persistent of 
encroachments and change in land use from open spaces to other residential/commercial. [7] claim that, it is the failure of "top down" management approach towards public open spaces management and recommended that, households "owning plots surrounding the open spaces should be entrusted with the ownership of such public space and should also be responsible and accountable to the environmental cleanliness of such spaces. Open spaces should be designed and designated for specific activities ranging from children to adults' games/social activities". This implies that, involvement of households in management, planning and designing use values of open spaces that consider the socioeconomic needs of different groups of people could be the solution towards conservation of open spaces. However, to what extent the surrounding or local community perceives on the benefits, costs and quality of open spaces as a motivation for being entrusted with the ownership and or involvement towards conservation of public open spaces is still a conundrum which researchers need to address.

Consequently, to have appropriate modality for involving households in conservation of open spaces, it is very important to understand characteristics of household community towards conservation of open spaces. This study intends to determine households' awareness and perceptions towards open spaces conservation, with a particular focus on their willingness and factors influencing their willingness to participate in conservation of open spaces.

\section{Materials and Methods}

\subsection{Study Area}

This study was conducted in four hamlets of Dar es Salaam city which included: Mkunguni, Minazini, Charambe and Sharifushamba in Hananasifu, Makumbusho, WestUpanga and Ilala wards respectively. Hananasifu and Makumbusho wards are in Kinondoni Municipality while West-Upanga and Ilala are in Ilala Municipality, as shown in Figure 1. According to [9], Dar es Salaam Region lies along the Western Coast of the Indian Ocean. It is situated between latitudes 6.36 and 7 degrees South of the Equator and between longitude 33.3 and 39 degrees to the East of Greenwich. It boarders Pwani Region in the North, West and South while to the East, there is the Indian Ocean as shown in Figure 1.

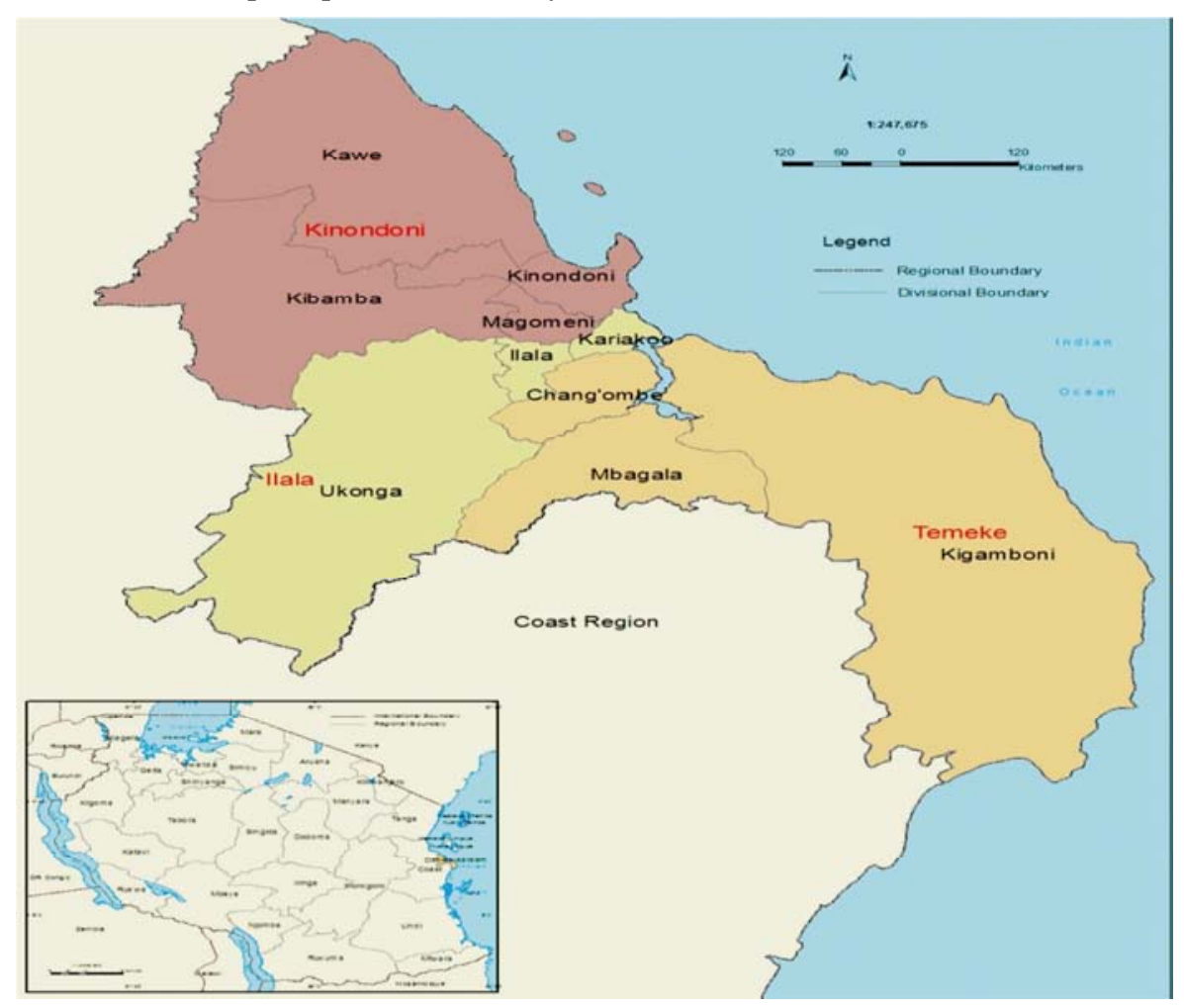

Figure 1. A Map of Dar es Salaam Region, 2013.

Dar es Salaam has an average land and population size of 4364541 and 1393 square kilometres respectively, the major economic activities include: internal trade, manufacturing, tourism, transport and communication, urban agriculture, forestry and fishing, mining and quarry, utility services, construction, finance and insurance, public administration and education.

Selection of study area above was based on the presence of open spaces with different status in Ilala and Kinondoni municipalities. According to the Kinondoni and Ilala municipal reports, a total number of 160 and 98 open spaces have been identified respectively. However, only 9 and 76 among the identified open spaces in Kinondoni and Ilala respectively still exist while the rest were either converted to other land uses or encroached. 


\subsection{Data Collection}

The study used both primary and secondary data. For primary source, a sample of 120 households was randomly selected consisting of 30 households from each hamlet (Mtaa). According to [10] the minimum sample size enough for studies using statistical data analysis is 30 . The sampling process involved identification and grouping of open spaces purposively basing on their locality and current status such that either working as open space or encroached, vandalized and changed into other land uses with reference to Kinondoni and Ilala municipalities. The four open spaces were then randomly selected from two groups whereby each municipality included two open spaces based on the assumption that one is working and another is not working. Following this process, open spaces at Mkunguni, Minazini, Sharifushamba and Charambe streets were selected. Finally, following on the randomly selected open spaces, their equivalently 30 respondents here in referred as households were randomly selected from each street as representatives.

Structured household survey questionnaire with likert scale of three items which are Agree, Neutral and Disagree was administered to respondents to measure their awareness and willingness to participate in conservation of open spaces. Key informants and focus group discussion were conducted in order to supplement information on all matters which respondents were required to respond in households' survey questionnaire. The households' demographic and socioeconomic variables were also included such as age, sex, education and income condition to help in contextualisation of the findings so as to develop good recommendations.

Secondary data consisted of both qualitative and quantitative and were collected from Dar es Salaam Regional Office, Ministry of Land Housing and Human Settlements Development, Kinondoni and Ilala municipal councils, journals, books, reports, internet publications, websites, Sokoine National Agriculture Library (SNAL), wards and each hamlet visited.

\subsection{Data Analysis}

Data analysis involved qualitative and quantitative analysis. Statistical Package for Social Sciences (SPSS) computer software was used during analysis of the data. Qualitative analysis involved content analysis of the data from direct observation and group discussions. Quantitative analysis involved both descriptive and inferential statistical analyses. Quantitative socio-economic data were analysed using descriptive statistical methods (Frequency distribution). Frequency distribution tables and numerical descriptive values (Percentages) were used to summarise the data. This was carried out in order to understand distribution of respondents and to explain socio-economic characteristics of the community close to the open spaces. The inferential statistical analysis in this study aimed at finding factors that might influence households' willingness to participate in open spaces conservation. Cross tabulations chi-square was used to assess willingness to participate while categorical optimal scaling regression analysis was used to determine latent factors influence willingness to participate in open spaces conservation. The dependent summated categorical variable used was willingness to participate in conservation of open space. Given the nature of data collected and its likert scale type, quantitative analysis could be done with ordinal, multinomial and categorical regression analysis. However, the categorical regression analysis was selected because of advantages it has over the Multinomial and ordinal regression models. This analytical technique performs a better job than other well known methods in statistics and especially when the number of observations in numeric variables is reduced much to smaller categories [11]. Also categorical regression analysis can run with least assumptions like normality of the predictor variables, smaller rather than larger sample size and only one coefficient is needed for predictor variables [12].

Households' perceptions were determined by computing and analysing summated scores of all variables explaining similar things, this approach is in line with [13-15]. For example, to determine perceived costs from open spaces conservation, four variables such as "cleanliness and maintenance cost", "irrespective uses protection cost", "vandalism and encroachments protection cost" and "Social security cost" were used. Perceived benefits from open spaces conservation were determined by eight variables such as "Scenic resources conservation", "Good air quality", "Good water quality", "healthy and psychological relief", "Access to play grounds for children and other members", "Conserve flora and fauna", "Provide refuge during natural or artificial disaster" and "Access for research and learning". Finally, Perceived quality of existing open spaces was determined by five variables "Poor hygienic condition", "Spurred of non open spaces related activities", "Poor security and infrastructures", "Poor services and against the need" and "Poor environmental conditions". The responses were on a Likert of three points such that, one for disagree, two for neutral and three for agree and the corresponding expected summary scores are presented and labelled according to [13] as illustrated in Table 1.

Table 1. Anticipated summary scores and value labels of perceived costs, benefits, quality and willingness to participate.

\begin{tabular}{lllll}
\hline S/N & Variable & \multicolumn{3}{l}{ Summated Scores } \\
\hline & & Agree & Neutral & Disagree \\
\hline 1. & Perceived costs & 12 & 8 to $<12$ & 4 to $<8$ \\
2. & Perceived benefits & 24 & 16 to $<24$ & 8 to $<16$ \\
3. & Perceived quality & 15 & 10 to $<15$ & 5 to $<10$ \\
4. & Willingness to participate & 18 & 12 to $<18$ & 6 to $<12$ \\
\hline
\end{tabular}

The Statistical Packages for Social Sciences software was used during data analysis. Cross tabulations chi-square was used to assess willingness to participate while categorical optimal scaling regression analysis was used to determine latent factors influence willingness to participate in open spaces conservation. The Regression model for categorical variable is expressed as a linear regression model for transformed variables as follows [16]; [11]; [12].

$$
\varphi_{\mathrm{r}}(\mathrm{y})=\sum \beta_{\mathrm{j}} \varphi_{\mathrm{j}}\left(\mathrm{X}_{\mathrm{j}}\right)+\mathrm{e}
$$




$$
\mathrm{j}=1
$$

Whereby; $\varphi_{\mathrm{r}}$ (y) is the vector of observations for transformed response variable, $\beta_{\mathrm{j}}$ is the regression coefficients, $j=1 \ldots . . J$ is the number of predictor variables, $\varphi_{j}$ $\left(\mathrm{X}_{\mathrm{j}}\right)$ is the transformation function of the predictor variable $\left(\mathrm{X}_{\mathrm{j}}\right)$ and $\mathrm{e}$ is the error vector.

\section{Results and Discussions}

\subsection{Description of Socio-Economic Characteristics of Households}

Households' characteristics that were analyzed are socio- economic and demographic. Socio-economic characteristics were age, sex, marital status, level of education, duration of Residence and main source of income while demographic characteristic analyzed was only households' location.

\subsubsection{Age and Sex}

Findings show that the age of respondents ranged from 20 to above 60 years old (Table 2). The adult group being the majority implying that, majority of the respondents were matured enough to understand and take part in decision making process for a particular community while youth are very energetic, high risk taking and fast learners [17-18].

Table 2. Distribution of households' age group, sex, marital status, education level, duration of residence and income source ( $n=120)$.

\begin{tabular}{|c|c|c|c|c|c|c|}
\hline $\mathbf{S} / \mathbf{N}$ & Variable & Categorical values & Percentage & $\mathrm{X}^{2}$ Value & Degrees of freedom & Level of significance \\
\hline \multirow{7}{*}{1.} & \multirow{7}{*}{ Age group } & $20-30$ & 19.2 & \multirow{7}{*}{33.60} & \multirow{7}{*}{5} & \multirow{7}{*}{0.000} \\
\hline & & $31-40$ & 25.8 & & & \\
\hline & & $41-50$ & 28.3 & & & \\
\hline & & $51-60$ & 14.2 & & & \\
\hline & & $61-70$ & 9.2 & & & \\
\hline & & $>70$ & 3.3 & & & \\
\hline & & Total & 100 & & & \\
\hline \multirow[t]{3}{*}{2.} & \multirow[t]{3}{*}{ Gender } & Female & 35.8 & \multirow[t]{3}{*}{9.63} & \multirow[t]{3}{*}{1} & \multirow[t]{3}{*}{0.002} \\
\hline & & Total & 100 & & & \\
\hline & & Married & 70 & & & \\
\hline \multirow{4}{*}{3.} & \multirow{3}{*}{ Marital status } & Never married & 21.6 & \multirow{4}{*}{140.00} & \multirow{3}{*}{3} & \multirow{3}{*}{0.000} \\
\hline & & Widow & 6.7 & & & \\
\hline & & Divorced & 1.7 & & & \\
\hline & \multirow{7}{*}{ Education level } & Total & 100 & & \multirow{8}{*}{4} & \multirow{8}{*}{0.000} \\
\hline \multirow{6}{*}{4.} & & Primary & 42.5 & \multirow{6}{*}{68.42} & & \\
\hline & & Tertiary & 4.17 & & & \\
\hline & & Adult education & 8.33 & & & \\
\hline & & Higher learning & 11.67 & & & \\
\hline & & Total & 100 & & & \\
\hline & & $1-15$ & 25.83 & & & \\
\hline \multirow{3}{*}{5.} & \multirow{3}{*}{ Residence duration } & $16-30$ & 42.51 & \multirow{3}{*}{28.20} & & \\
\hline & & $31-45$ & 23.33 & & \multirow[t]{2}{*}{3} & \multirow[t]{2}{*}{0.000} \\
\hline & & $>45$ & 8.33 & & & \\
\hline \multirow{5}{*}{6.} & \multirow{5}{*}{ Income source } & Total & 100 & \multirow{5}{*}{21.60} & \multirow{5}{*}{2} & \multirow{5}{*}{0.000} \\
\hline & & Employment & 43.3 & & & \\
\hline & & Business & 43.4 & & & \\
\hline & & Others & 13.3 & & & \\
\hline & & Total & 100 & & & \\
\hline
\end{tabular}

Sex distribution shows that, of the 120 total respondents, $64.2 \%$ were males and $35.8 \%$ were females (Table 2 ). The analysis of gender distribution for this study was of paramount importance since gender based labour distribution has a lot of implications particularly in African Countries context where women are often forgotten to participate in important decision concerning community's development [18]. This assertion is clearly explained in the work of various researchers [18-19]. The authors argue that, in developing countries, males have easy access to information, oversee the households' decision making process and they often have higher participation rates for most activities than female [18-19]. Contrary, males are less sensitive and concerned with environment and pro-environmental behaviour compared to females [20-21]. Therefore, the finding on gender distribution could form a base for fairness during awareness raising and attitudinal diagnoses towards open spaces conservation initiatives in developing countries, where this study could act as a reference.

\subsubsection{Marital Status and Education Level}

The study shows that about $70 \%$ of the respondents were married. Besides, understanding of marital status distribution was of paramount importance for this particular study because it influences decision making process towards environmental conservation interventions. This is according to [21] who argue married that people tend to be less sensitive and more satisfied with environmental conditions than single persons. Thus, understanding marital status distribution is intended to give a base during planning and 
implementation of interventions towards conservation of open spaces in developing countries where this pattern exists.

On education, the study shows that, majority of the respondents (about 42.5\%) had attained primary school education level (Table 2). However, the finding differs from what [22-23] suggest. The authors noted that in urban areas majority of the respondents had acquired higher degree and tertiary education respectively. This study's finding indicates that, majority of the respondents in the study area had lower education level in comparison to standard world cities.

In addition some studies [18, 22] revealed that, under constant conditions the higher the level of education the higher is the knowledge on the importance of conserving environmental resources for effective and sustainable urban living. However, some studies found no positive association between level of education and knowledge or attitude to conserve environmental resources in urban areas. The finding from this study provides basic information for planning and fairness in implementing conservation initiatives like raising awareness towards conservation of open spaces.

\subsubsection{Residence Status and Income Sources}

The study revealed that about $43 \%$ of the respondents have lived in the study area for an average of 20 years whereas quite a few have lived for more than 40 years (Table 2). Contrary to what [24] noted where majority of the respondents in his study lived more than 30 years while quite a few lived less than 10 years.

It was not clear from our findings what are the reasons for this since it was not within our objective; however the possible cause of this difference might be location specific characteristics differences, such that urban areas like Dar es Salaam where population grows rapidly with development involving relocation of local residences, there might be movement of households from one location to another. However, duration of stay of a household in a specific location has implications in the conservation of status of that area [24]. The authors claim that indigenous people who have lived for a long time in the area are more committed to resource conservation than residents who recently moved to the area. Therefore, this finding provides an opportunity for appropriate planning and fairness in implementing conservation initiatives with respect to the nature and trends of local residents in fast growing cities like that of Dar es Salaam.

Majority of the respondents $(>80 \%)$ in the study area are either employed or engaged in cash generating businesses (Table 2). This finding is similar to that of [9] where it was reported that majority of the residents in Dar es Salaam depend on business as major source of income. Many studies like [25-27] indicate that, income generating activities of local residents influence the environmental resource conservation. [28] found that expansion of land for agricultural activities due to investments made by households with high income, had been threatening conservation of Selous-Niasa Miombo woodland ecosystem in Nachingwea, Tanzania. Thus from the finding of this study it can be learnt that the rate of migration and pressure on land for new settlements, business centres and petty trade increases and threatens conservation of open spaces in Dar es Salaam City.

\subsection{Households'Awareness on the Objectives and Rules Towards Conservation of Open Spaces}

\subsubsection{Awareness on the Objectives of Open Spaces}

The study noted that, most of the respondents (96.7\%) were aware of the specific types of open spaces. The well known open spaces included: recreational parks, sports grounds and playing fields as the types of open spaces. However, very few (about 40\%) were familiar with forest wood trees (Table 3). Furthermore, in the case of the objectives of conservation of open spaces, the study revealed that, most respondents $(99.9 \%)$ were aware on the function of open spaces in providing recreational services and emergency assembling area in a crowded city like Dar es Salaam. Besides, more than $95 \%$ of the respondents were aware on the function of open spaces in providing education services, health and psychological relief and conserving natural and artificial beauty (Table 3 ).

Table 3. Households' awareness on the types and functions of open spaces $(n=120)$.

\begin{tabular}{|c|c|c|c|c|c|}
\hline $\mathbf{S}$ & Variables & Percentage & $\mathrm{X}^{2}$ Value & Degree of freedom & Level of significance \\
\hline & Type of open spaces & & & & \\
\hline 1. & Recreation parks & 95.8 & 100.83 & 1 & 0.000 \\
\hline 2. & Forest wood trees & 40 & 3.20 & 2 & 0.202 \\
\hline 3. & Sports grounds and playing fields & 96.7 & 216.65 & 2 & 0.000 \\
\hline 4. & Flooding areas & 60 & 39.65 & 2 & 0.000 \\
\hline 5. & Burial grounds & 55 & 35.15 & 2 & 0.000 \\
\hline \multirow[t]{2}{*}{6.} & Wetlands & 63 & 48.65 & 2 & 0.000 \\
\hline & Function/importance of open spaces & & & & \\
\hline 7. & Conserve scenic resources & 98.3 & 112.13 & 2 & 0.000 \\
\hline 8. & Conserve flora and fauna & 75 & 94.20 & 2 & 0.000 \\
\hline 9. & Conserve sources of water & 63.3 & 49.40 & 2 & 0.000 \\
\hline 10. & Protect hazardous areas & 70 & 72.80 & 2 & 0.000 \\
\hline 11. & Provide parks and recreational areas & 100 & & & \\
\hline 12. & Conserve archaeological resources & 99.2 & 116.033 & 1 & 0.000 \\
\hline 13. & Provide buffer zone between land uses & 97.5 & 108.30 & 1 & 0.000 \\
\hline 14. & Provide improved air quality & 97.5 & 708.30 & 1 & 0.000 \\
\hline
\end{tabular}




\begin{tabular}{llllll}
\hline $\mathbf{S}$ & Variables & Percentage & $\mathbf{X}^{2}$ Value & Degree of freedom & Level of significance \\
\hline 15. & Provide improved water quality & 64.2 & 52.35 & 2 & 0.000 \\
16. & Healthy and psychological relief & 95.8 & 211.05 & 2 & 0.000 \\
17. & Sports grounds and playing fields & 99.2 & 116.033 & 1 & 0.000 \\
18. & Escapement from hazards/emergency & 100 & & & 0.000 \\
19. & Provide area for research and learning & 96.7 & 104.53 & 1 & \\
\hline
\end{tabular}

The above finding implies that, in general, awareness on the functions and types of open spaces amongst the City's residents is high. However, such awareness is restricted to some of the mentioned open spaces such as recreational parks, sports grounds and playing fields compared to forest wood trees, flooding areas, burial grounds and wetlands. The reason behind that awareness of the specific types of open spaces could be that, these are commonly close and available within their premises and can be easily accessed. Besides, socio-economic and environmental benefits associated with parks, playing field and sports grounds are well known by local residents. The finding is similar to other environmental conservation related studies including those of [24-25, 27 , 29-30] who found high degree of awareness of local community in understanding issues and importance of particular environmental resources such as urban open spaces, marine and coastal resources, forest, water and farmland. The authors showed that awareness of the studied population had also significant influence on their perceptions to support environmental conservation initiatives.

\subsubsection{Awareness on Rules and Regulations Governing Open Spaces}

The study finding shows that, about $67.5 \%$ of respondent are aware on the Urban Planning Legislation as tool for enforcing and governing open spaces in urban area. However, very few (about 14.2\%) agreed to be aware on the other rules for enforcement and governance of open spaces as shown below (Table 4). Also, the study shows that, $99.2 \%$ of the respondents agreed that local community are most responsible in conservation of open spaces followed by government authorities.

Table 4. Households' awareness on laws and responsibilities $(n=120)$.

\begin{tabular}{|c|c|c|c|c|c|}
\hline $\mathbf{S} / \mathbf{N}$ & Variable & Percentage & $\mathrm{X}^{2}$ Value & Degree of freedom & Level of significance \\
\hline & Laws & & & & \\
\hline 1. & Urban Planning Act, 2007 & 67.5 & 72.15 & 2 & 0.000 \\
\hline 2. & Environmental Management Act, 2004 & 66.7 & 76.20 & 2 & 0.000 \\
\hline 3. & Local Government Act No.(7) (8), 1982 & 63.3 & 64.8 & 2 & 0.000 \\
\hline 4. & Other rules & 14.2 & 60.45 & 2 & 0.000 \\
\hline & Responsible body & & & & \\
\hline 5. & Municipal Councils & 95.8 & 100.83 & 1 & 0.000 \\
\hline 7. & Ministry of Land & 95.8 & 100.83 & 1 & 0.000 \\
\hline 8. & Local Community & 99.2 & 116.03 & 1 & 0.000 \\
\hline 9. & Nongovernmental Organizations & 70 & 78.65 & 2 & 0.000 \\
\hline
\end{tabular}

However, about $94 \%$ of the respondents disagreed if there is collaboration between those perceived institutions for overseeing open spaces in urban area and local community (Table 5). The above finding implies that, local community are aware about the rules and regulations and are ready to take responsibilities to conserve open spaces. Furthermore, there is lack of collaboration between different actors with local community in management of open spaces and finally, more education is needed to raise awareness of the local community about the laws and roles of different actors towards conservation of open spaces.

Table 5. Households' awareness on collaboration between institutions and local community regarding open spaces conservation ( $n=120)$.

\begin{tabular}{|c|c|c|c|c|c|}
\hline $\mathbf{S} / \mathbf{N}$ & Variable & Agree (\%) & Neutral (\%) & Disagree (\%) & Standard deviation \\
\hline 1. & Ministry of Land & 7.5 & 0.8 & 91.7 & 0.53446 \\
\hline 2. & NEMC & 4.2 & 1.7 & 94.2 & 0.41808 \\
\hline 3. & Municipal Council & 8.3 & 0.8 & 90.8 & 0.56005 \\
\hline 4. & Ward & 17.5 & 1.7 & 80.8 & 0.76623 \\
\hline
\end{tabular}

Many studies argue that, understanding of the rules and regulations which govern management of environmental resources influence local community perception in supporting conservation initiatives. For example, the study by [25] found awareness of local community on rules and regulations governs coastal resources management had positive attitude towards establishment of marine protected area in coastal region of Tanzania.

\subsection{Households' Perception Towards Conservation of Open Spaces}

\subsubsection{Perceived Conservation Costs Towards Open Spaces Conservation}

The summary scale of 4 Likert statements on perceived cost from conserving open spaces was analysed. The expected values of summed score for perceived costs are 
presented in Table 1. The study finding shows that, most of the respondents $(95 \%)$ have positive perception on cost associated with open spaces conservation and $2.5 \%$ disagreed while the rest were neutral/undecided (Table 6). Similar finding was obtained by [25] who found that $39.18 \%$ of the respondents perceived that, conservation of marine resources are associated with cost. However, these respondents who had positive perception on conservation costs had negative attitude to support marine protected area establishment.

Table 6. Perception on conservation cost, conservation benefits and quality of existing open spaces $(n=120)$.

\begin{tabular}{lllllll}
\hline S/N & Variable & Agree (\%) & Neutral (\%) & Disagree (\%) & Total (\%) & Standard deviation \\
\hline 1. & Perceived cost & 95 & 2.5 & 2.5 & 100 & 1.07375 \\
2. & Perceived benefits & 70.8 & 29.19 & 0 & 100 & 100 \\
3. & Perceived quality & 73.3 & 25 & 1.7 & 1.93482 \\
\hline
\end{tabular}

The above finding implies that, local community have positive perception on the cost associated with conservation of open spaces. They are aware that, open spaces need maintenance, regular cleanness, protection and social security which had been reflected as the direct conservation costs by local community. Therefore, this finding will provide a base for fairness to local community during participatory open spaces conservation initiatives.

\subsubsection{Perceived Benefits from Conserving Open Spaces}

The summary scale of 8 likert statements on perceived benefits from conserving open spaces was analysed. The expected values of summed scores for perceived benefits are as shown in Table 1 . The study finding shows that, $70.81 \%$ of the respondents perceive conservation of open spaces is beneficial (Table 6), that is open spaces conserve and beautify both natural and artificial environment, provides recreational, sports and playing fields, providing fresh air, health and psychological relief and other more services as described in section 3.2.

The above finding is similar to other studies. For example, [25] claim that, about $47.92 \%$ of households perceived on the available benefits associated with marine resources conservation such as economical and ecological benefits. Furthermore, [31] found that, majority of the households in Yokohama perceived that conservation activities will enhance residents' social interaction for that being a motive to participate in conservation activities. The finding implies that majority of the respondents are aware and positive on the benefits that may be accrued from sustainably management of urban open spaces.

\subsubsection{Perceived Quality on Existing Open Spaces}

The summary scale of 5 likert statements on perceived quality of existing open spaces was analysed. The expected values and labels of summary scores for perceived quality are as shown in Table 1. The finding shows that about $73.3 \%$ perceive that, existing open spaces have no good quality while the rest were undecided/neutral (Table 6). Similarly, the perceived quality of open spaces has been a concern even in developed countries, a study by [32] argues on different management approaches and mainly they insisted on multistakeholders involvement including local community. In South Africa, a study by [33] argues that, neglecting the general public perceptions of the environment may result in planning approaches and decisions that are inconsistent with a community's needs and desires. The finding implies that, respondents are sensitive and concerned with the existing poor quality of open spaces. Therefore, it is necessary to think of planning and designing open spaces which will serve both users satisfactions and the environmental conservation purposes since perceived quality has influence on individual decision to support integrity of the product $[2,34]$.

\subsection{Households' Willingness to Participate in Conservation of Open Spaces}

The households' willingness to participate in conservation of open spaces was assessed using six likert questions as variables which were coded and the values entered into the SPSS, followed by computation of Likert scale (willingness to participate in open spaces conservation) for all variables. The values and labels of summated score for willingness to participate are presented in Table 1 . The Respondents were asked if they are willing to participate in various activities like awareness rising, visiting and paying entrance fees, reporting open spaces abuse, volunteer cleanliness and maintenance, contributing cash and collaborating with government for sustainable conservation of open spaces. The cross tabulation was used to assess the households' willingness to participate in conservation of open spaces and the association between willingness to participate and most of the respondents who responded to households survey questionnaire was determined as shown in Table 7 . The finding shows that $55.8 \%$ of the respondents were willing to participate in conservation of open spaces while the rest were neutral/undecided.

Table 7. Household willingness to participate in open spaces conservation.

\begin{tabular}{|c|c|c|c|c|c|c|}
\hline \multicolumn{7}{|c|}{ Mtaa } \\
\hline Summated scores & Value labels & Mkunguni $(n=30) \%$ & Minazini $(n=30) \%$ & Sharifushamba $(n=30) \%$ & Charambe $(n=30) \%$ & Total $(n=120) \%$ \\
\hline 0 & Disagree & 0 & 0 & 0 & 0 & 0 \\
\hline $12-16$ & Neutral & 36.6 & 30 & 33.4 & 76.6 & 44.2 \\
\hline Total & & 100 & 100 & 100 & 100 & 100 \\
\hline
\end{tabular}

Total number of households $=120$, Pearson Chi- square $=26.105, \mathrm{df}=12, \mathrm{p}=0.010$ 
This finding is similar to other related studies, for example, [22] found that about $76 \%$ of the respondents were willing or very willing to participate in planning, management and design of urban green spaces in Guangzhou, China. [31] found that more than half of respondents were willing to participate in various conservation activities in urban area like tree planting and nature conservation in Japan. In addition, high willingness to participate in conservation of fresh water turtle and tropical urban river was demonstrated by local community in Sri Lanka and Malaysia respectively [21, 35].

In Tanzania, the finding from this study is similar to [7] who showed that local community were willing to create and control their own open spaces because of understanding of the need and meaning of such spaces in their residence. Studies like [30] showed that, residents' willingness to participate in forest conservation increases with increase level of education in Mufindi District. [25] found that some local residents were willing to participate in conservation initiatives such as establishment of marine protected areas due to positive perceived benefits. [27] showed that, local community demonstrated willingness to participate in farmland conservation by adopting various conservation initiatives in Irangi hills, Dodoma Region.

This finding implies that, local community in Dar es Salaam are willing to participate in open space conservation in spite of their awareness of the cost they would incur so as to improve the degraded quality of the particular sites. It can be argued that, the general level of awareness and perceptions on the quality and the socio- economic benefits of having substantial open spaces contributed much on their willingness to participate in conservation of open spaces. However, the number of the respondents could increase when awareness programmes are developed.

Furthermore, the finding shows a significant difference on willingness to participate in open spaces conservation between respondents in Mkunguni, Minazini, Sharifushamba and Charambe at $\left(\chi^{2}=26.105, \mathrm{df}=12, \mathrm{P}<0.05\right)$. Minazini has the highest willingness to participate $(70 \%)$ in open spaces conservation while Charambe had the lowest $(23.3 \%)$. The possible reasons could be explained from what was revealed during group discussions. During the discussions it was revealed that, many respondents in Minazini had high experience on the trend of open spaces conversion to other land uses, encroachments and other disturbances to open spaces reduction problem in their area. Therefore, their negative perceptions on the way local authorities manage open spaces have encouraged them to have higher willingness to participate in conserving open spaces in their areas. Also, during discussions it was revealed that majority of the respondents in Charambe were new in the area while contributing cash for security and cleanliness of their local area including open spaces. Therefore, respondents in Charambe have low impetus and are less willing to participate in conservation of existing open spaces that could be associated with fear on their time and extra cost when participating in open spaces conservation.

\subsection{Households' Characteristics Influencing Willingness to Participate in Conservation of Open Spaces}

It should be mentioned that, in order to determine how the households' characteristics influence the willingness of the individual household to participate in conservation of open spaces the Categorical regression model with the help of Statistical Package for Social Sciences (SPSS) was used during analysis. The dependent variable was willingness to participate in conservation of open spaces while the independent variables were perceived costs, perceived quality, perceived benefits, respondents' age, gender, marital status, education level, duration of Residence, and source of income. The results of categorical regression analysis are summarised in Tables 8 and 9.

The result gave $\mathrm{R}^{2}=0.439$ which shows that about $43.9 \%$ of willingness to participate in conservation of open spaces is explained by transformed values of independent variables included in the regression equation. Furthermore, the analysis of variance (ANOVA) gave the value of $F=2.040$, that corresponds to the 0.005 level of significance, which means that the categorical regression model adapted well to the transformed data (Table 8).

Table 2. Categorical regression ANOVA table.

\begin{tabular}{llllll}
\hline & Sum of Square & df & Mean square & F & Level of significance \\
\hline & & & & & \\
Regression & 52.688 & 33 & 1.597 & 2.040 & 0.005 \\
Residual & 67.312 & 86 & 0.783 & & \\
Total & 120.000 & 119 & & & \\
\hline
\end{tabular}

Table 9. Coefficients of categorical regression.

\begin{tabular}{|c|c|c|c|c|c|c|}
\hline \multirow[b]{3}{*}{$\mathbf{S} / \mathbf{N}$} & \multirow{3}{*}{ Predictor variables $(\mathbf{X j})$} & \multicolumn{5}{|c|}{$R^{2}=0.439$} \\
\hline & & \multicolumn{2}{|c|}{ Standardized Coefficients } & \multirow{2}{*}{ df } & \multirow{2}{*}{$\mathbf{F}$} & \multirow{2}{*}{ Sig. } \\
\hline & & Beta & Std. Error & & & \\
\hline 1. & Perceived cost & -0.147 & 0.086 & 4 & 2.963 & 0.024 \\
\hline 2. & Perceived quality & 0.180 & 0.091 & 6 & 3.878 & 0.002 \\
\hline 3. & Perceived benefit & 0.454 & 0.086 & 5 & 27.698 & 0.000 \\
\hline 4. & Respondent age & -0.451 & 0.108 & 5 & 17.418 & 0.000 \\
\hline
\end{tabular}




\begin{tabular}{|c|c|c|c|c|c|c|}
\hline \multirow[b]{3}{*}{$\mathbf{S} / \mathbf{N}$} & \multirow{3}{*}{ Predictor variables $(\mathbf{X j})$} & \multicolumn{5}{|c|}{$R^{2}=0.439$} \\
\hline & & \multicolumn{2}{|c|}{ Standardized Coefficients } & \multirow{2}{*}{ df } & \multirow{2}{*}{$\mathbf{F}$} & \multirow{2}{*}{ Sig. } \\
\hline & & Beta & Std. Error & & & \\
\hline 5. & Respondent's gender & -0.064 & 0.098 & 1 & 0.431 & 0.513 \\
\hline 6. & Respondents' marital status & -0.293 & 0.099 & 3 & 8.821 & 0.000 \\
\hline 7. & Respondent's education level & 0.225 & 0.088 & 4 & 6.488 & 0.000 \\
\hline 8. & Duration of Residence & 0.249 & 0.103 & 3 & 5.847 & 0.001 \\
\hline 9. & Major source of income & -0.382 & 0.099 & 2 & 14.832 & 0.000 \\
\hline
\end{tabular}

Dependent variable: Willingness to participate in conservation of open spaces

The study result shows that several socio-economic factors had positive and negative influence on households' willingness to participate in conservation of open spaces. The factors observed to influence positively households' willingness to participate in open spaces conservation include perceived quality, perceived benefits, Duration of Residence and level of education (Table 9).

The result shows that, perceived quality is statistically significant $(\mathrm{P}=0.002)$ and positive $($ Beta $=0.180)$ regression coefficient with households' willingness to participate in conservation of open spaces. This implies that, households or local community are most concerned with the existing quality of open spaces and are motivated to participate for improvement. These findings are similar to those reported by [31] for Yokohama where in Japan local community believed that their participation in conservation initiative will influence the quality of urban green spaces.

The result also shows that, perceived benefit is statistically significant $(\mathrm{P}=0.000)$ and positive $($ Beta $=0.454)$ regression coefficient with households' willingness to participate in conservation of open spaces. This implies that, for a unit increase in understanding the benefits associated with open spaces there is a unit increase of willingness to participate in conservation of open spaces among the local community particularly households. These results are similar to [31] who showed that, local community believed that participation in conservation of green spaces will benefits them through increasing social interaction and collaboration among themselves and the government. Furthermore, related study by [25] came with the same observation such that local community were positive on establishment of marine protected areas in coastal of Tanzania because of the expected perceived benefits.

The result shows that, level of education is statistically significant $(\mathrm{P}=0.000)$ and positive $(\mathrm{Beta}=0.225)$ regression coefficient with households' willingness to participate in conservation of open spaces. This implies that people with higher level of education are more willing to participate in conservation of open spaces. These results are in agreement with the observations by [22] which showed that respondents with a university and higher degree had stronger willingness to participate than those with an upper secondary education in conservation of urban green spaces in China. Furthermore, positive influence of education towards conservation of environmental resources is similar to the findings of $[19,21$, $24,35]$ who claim that education is positively influence local community's participation in environmental resources conservation.
Last factor which had positive influence and statistically significant $(\mathrm{P}=0.001)$ and positive $(\mathrm{Beta}=0.249)$ regression coefficient is duration of Residence, also known as duration of residence with households' willingness to participate in conservation of open spaces. This implies that the longer the household lived in the area the more willing to participate in 00conservation of open spaces. These results are similar to the observations by [24] which showed that, local community who stayed longer in the village are more interested in conserving environmental resources such as forest in Mufindi District, Tanzania.

However, the result shows some factors that negatively influenced households' willingness to participate in conservation of open spaces, include perceived cost, age, gender, marital status and source of income (Table 9). Perceived cost is statistically significant $(\mathrm{P}=0.024)$ and negative (Beta $=-0.147$ ) regression coefficient with households' willingness to participate in conservation of open spaces. This implies that, the higher the perceived costs by households the more unwilling to participate in open spaces conservation. This result is similar to the observations by [1] who showed that the lower the conservation costs the higher the willingness to participate in conservation programme and vice versa for the local community in Michigan, and [25] found that the higher the households perceived costs associated with MPA establishment, the greater the unwillingness to support its establishment in Tanzania. [19] also show that, the recreational demand is negatively associated with the cost of recreational trips in Greece.

Age was also statistically significant $(\mathrm{P}=0.000)$ and negative (Beta $=-0.451)$ regression coefficient with households' willingness to participate in conservation of open spaces. This implies that, as households' age increase the more unwilling to participate in conservation of open spaces. These results are similar to the observations found by [19, $21-22,24,31,35]$ who showed that older people are unwilling to participate in or supporting environmental resources conservation compared to young people.

Gender was not statically significant $(\mathrm{P}=0.513)$ and negative (Beta $=-0.064$ ) regression coefficient with households' willingness to participate in conservation of open spaces. This result can be compared with other related studies like [19] who found that, sex had similar effect as age that is men are more interested in participating in recreation activities than female. Furthermore, participation of males in recreation activities could be influenced by increase in age, income and average family size [19]. This result implies that, given the majority of respondents being males their willingness to participate in open spaces conservation will be 
decreasing with increasing in age under constant conditions of other factors.

Marital status was statistically significant $(\mathrm{P}=0.000)$ and negative (Beta $=-0.293$ ) regression coefficient with households' willingness to participate in conservation of open spaces. This result can be compared with related studies such as [21] who found that willingness to participate in conservation was influenced by age and marital status likewise. It had been shown by [21] single and younger respondents were very sensitive and concerned in environmental conditions compared to married respondents who were mostly elder. This result implies that, the more the number of married and aged people the less the sensitive and concerned people to environmental resources conservation like open spaces.

Source of income was statistically significant $(\mathrm{P}=0.000)$ and negative $($ Beta $=-0.382$ ) regression coefficient with households' willingness to participate in conservation of open spaces. Studies conducted by other researchers like [26] claim that, respondents whose income depend most on the existing environmental resources will have low support on the particular environmental resource conservation initiatives. However, different result was obtained by [25] who claimed that, poor respondents and most dependent on coastal resources for their livelihood had supported marine protected area establishment for conserving marine resources. This result implies that, respondents whose income generating activities might hinder open spaces sustainability are worried in supporting conservation of open spaces. Therefore, this information provides a base for fairness during planning and implementation of open spaces conservation initiatives.

\section{Conclusions}

Majority of local communities were aware of legislations governing conservation or management of various open but much conscious on the aspects of recreational parks, playing fields and playing grounds compared to other types of open spaces as they were directly connected to their daily life. This imply that, that unless the community awareness is raised on the values of open spaces, otherwise they will change most of the open spaces that have more ecological functions to the types that favour their immediate and direct needs. The study besides, highlights that unless the communities' perception is changed through conservation campaigns, the general perception amongst the communities studied is, government is a responsible organ in managing the open spaces. This therefore strengthens the need for conservation education to the local communities to win their willingness in the participatory strategies laid up by conservation agencies in enhancing sustainable and participatory management approaches in urban open spaces.

Local communities believe that it is expensive to conserve open spaces while at the same time agree that conservation costs cannot outweigh the anticipated benefits. They furthermore, argue that existing open spaces have poor quality and are poorly managed by the government. However, it is encouraging to see that their willingness to participate is rated positive even if such is negatively influenced by various socio-economic factors including; perceived cost, age, gender, marital status and source of income. It is therefore important for decision making bodies to consider these factors when designing the participatory management approaches to win communities' willingness to participate in the conservation efforts of the open spaces within urban settings. From the study we learn that participation of local communities in management of open spaces is likely to improve urban environment and the livelihoods of local community as demonstrated by this study. However, this will happen only if there is correct understanding of the factors that constrain the participation.

\section{References}

[1] McConnell, V. and Walls, M. (2005). The value of open space: evidence from studies of nonmarket benefits. [http://rff.org/RFF/Documents/RFF-REPORT-Open\% 20S paces.pdf] site visited on 18/7/2014.

[2] Haq A. M. S. (2011). Urban Green Spaces and an Integrative approach to sustainable environment. Journal of Environmental Protection 2: 601-608.

[3] Mensah, C. A. (2014). Destruction of urban green spaces: A problem beyond urbanization in Kumasi city (Ghana). American Journal of Environmental Protection 3 (1): 1-9.

[4] UN-HABITAT and UNEP (2005). The Sustainable Dar es Salaam Project 1992-2003. The Sustainable Cities Programme. Documentation Series No. 3. United Nations Human Settlements Programme, Nairobi, Kenya. 28pp.

[5] Persson, M. and Liljestrom, C. (2014). Development of Green Spaces in Dar es Salaam, Tanzania. Swedish University of Agricultural Sciences, Swedish. 81pp.

[6] Livin, M. H. (2012). Housing and land challenges in Tanzania. Prime Journal of Social Science 1 (6): 113-120.

[7] Vedasto, R. V. and Mrema, L. K. (2013). Architectural Perspective of Informalization of Formal Settlements: Case of Sinza Neighbourhood in Dar es Salaam. Online Journal of Social Sciences Research 2 (6): 151-172.

[8] Victor, M. A. M. and Makalle, A. M. P. (2003). Poverty and Environment: Impact Analysis of Dar es Salaam project on Sustainable livelihoods of urban poor. Journal of Social Sciences Research 2 (6): 151-152.

[9] URT (2014). Dar es Salaam Region Socio-Economic Profile 2014. Government Printers, Dar es Salaam, Tanzania. 171pp.

[10] Bailey, K. D. (1994). Methods of Social Research. The free Press Giller-Mac-Millan Publisher, New York. 813pp.

[11] Kooij, A. J. V. and Meulman, J. J. (2006). Prediction accuracy of regression with optimal scaling transformations: In: Prediction Accuracy and Stability of Regressions with Optimal Scaling Transformations. (Kooij, A. J. V.), Leiden University, Netherland. pp. 37-63. 
[12] Shrestha, S. L. (2009). Categorical Regression Models with Optimal Scaling for Predicting Indoor Air Pollution Concentrations inside Kitchens in Nepalese Households. Nepal Journal of Science and Technology 10: 205-211.

[13] Zaghloul, A. A., Al-Hussaini, A. F. and Al- Bassam, N. K. (2008). Intention to stay and Nurses' satisfaction dimensions. Journal of Multidisciplinary Healthcare 1: 51-58.

[14] Johns, R. (2010). Likert Items and Scales. Survey question bank methods fact sheet1.

[http://www.surveynet.ac.uk/sqb/datacollection/likertfactsheet. pdf] site visited on 10/3/2015.

[15] Boone, H. N. and Boone, D. A. (2012). Analyzing Likert Data. Journal of Extensions 50 (2): 1-5.

[16] Meulman, J. J. (1998). Optimal Scaling Method for Multivariate Categorical Data Analysis. SPSS White Paper No. 1. Leiden University, Netherlands. 12pp.

[17] Mrema, L. K. (2013). Creation and control of public open spaces: Case of Msasani Makangira informal settlement, Tanzania. Journal of Social Sciences Research 2 (7): 200-213.

[18] Lazaro, M., Shemdoe, R. S. and Emma, L. (2013). Community Perceptions and Willingness to Accept and Execute REDD+ Initiative: The Case of Pugu and Kazimzumbwi Forest Reserves, Tanzania. Cross Cultural Communication 9 (3): 48-54.

[19] Steriani, M. K. and Soutsas, K. P. (2005). Recreation Demand Model Construction Through the Use of Regression Analysis with Optimal Scaling. Mediterranean Journal of Economics, Agriculture and Environment 4 (4): 25-30.

[20] Zelezny, L. C., Chua, P. and Aldrich, C. (2000). Elaborating on gender differences in environmentalism. Journal of Social Issues 56 (3): 443-457.

[21] Chun, M. H., Suleiman, W. N. A. and Samah, M. A. A. (2012). A case study on public participation for a conservation of a tropical urban river. Political Journal of Environment Studies 21 (4): 821-829.

[22] Shan, X. Z. (2012). Attitude and willingness toward participation in decision-making of urban green spaces in China. Urban Forestry and Urban Greening 11: 211-217.

[23] Faleyimu, O. and Akinyemi, M. (2014). Socio Economic Assessment of Urban Forestry Respondents' income in Okiti Pupa, Ondo State, Nigeria. Journal of Applied Science in Environmental Management 18 (4): 603-607.

[24] Mpokigwa, M. K., Sangeda, A. Z. and Iddi, S. (2011). Toward communication, education and awareness rising for participatory Forest management: A case study of Mufindi district, Tanzania. International Journal of Social Forestry 4 (1): 17-31.
[25] Sesabo, J. K., Lang, H. and Tol, R. S. J. (2006). Perceived Attitude and Marine Protected Areas Establishment: Why Households' Characteristics Matters in Coastal Resources Conservation Initiatives in Tanzania. Working Paper No. 99. Research unit sustainability and global change, Hamburg University. 39pp.

[26] Mwanyoka, I. R. (2006). Evaluation of Community Participation in Water Resources Management: The Case of the East Usambara Biosphere Reserve to UNESCO mab young scientists program. [http://www.unesco.org/mab/doc/mys/2005/ tanzania.pdf] site visited on $10 / 6 / 2015$

[27] Kangalawe, R. Y. M. (2012). Land degradation, community perceptions and environmental management implications in the drylands of Central Tanzania [http://dx.doi.org/10.5772/45897] site visited on 8/6/2015.

[28] Ntongani, W. A., Munishi, P. K. T. and Mbilinyi, B. P. (2010). Land use changes and conservation threats in the eastern Selous-Niassa wildlife corridor, Nachingwea, Tanzania. African Journal of Ecology 48 (4): 880-887.

[29] Francis, M. (1987). Urban Open Spaces. In: Advances in Environment, Behaviors, and Design. (Edited by Zube, E. H. and Moore, G. T.). Environmental Design Research Association, New York. pp. 71-106.

[30] Sewando, P., Shimba, C. and Mndeme, D. (2011). An Assessment of Community Perception towards ownership of water projects. African Journal of Social Sciences 2 (4): 73 81 .

[31] Sakurai, R., Kobori, H., Nakamura, M. and Kikuchi, T. (2015). Factors influencing public participation in conservation activities in urban areas: A case study in Yokohama, Japan. Biological Conservation 184: 424-430.

[32] Lindgren, T. and Castel, P. (2008). Open space management in Residential areas - How it is organised and why. International Journal of Strategic Property Management 12: 141-160.

[33] Sutton, C. M. (2008). Urban Open Spaces: A case study of Msunduzi Municipality, South Africa. Dissertation for Award of MSc Degree at Queen's University, Kingston, Ontario, Canada, 129pp.

[34] Babin, B. J., Chebat, J. C. and Michon, R. (2004). Perceived appropriateness and its effect on quality, affect and behaviour. Journal of Retailing and Consumer Services 11: 287-298.

[35] Thiruchelvam, S. and Kirupakaran, S. (2010). Coastal communities' attitudes towards conservation of freshwater Turtle in Ampara District. Tropical Agricultural Research 21 (4): 427-434. 